\title{
ASSOCIATIONS BETWEEN AMPHIPODS (CRUSTACEA: AMPHIPODA) AND SEA ANEMONES (ANTHOZOA, ACTINIARIA)
}

\author{
WIM VADER \\ Troms $\phi$ Museum, University of Troms $\phi$ \\ N-9000 Troms $\phi$, Norway
}

SUMMARY

Published and unpublished records of amphipod-sea anemone associations are reviewed. They involve at least 22 amphipod species in 7 families, and 8 families of sea anemones. The associations are of 4 main types: protection only, ectocommensals, endocommensals and micropredators.

Morphological adaptations are not conspicuous, except for the specialised mouthparts of Acidostoma spp., but most obligate symbionts show inborn immunity against the toxic substances released by the host. Sex ratios are normal, sexual dimorphism small, and fecundity low compared to related free-living species.

The obligate commensal associates are usually host-specific, although able to survive in alternative hosts in the laboratory, while the micropredators and the facultative associates show low host specificity. The amphipod symbionts usually do not occupy the entire geographical and ecological range of their hosts' distribution.

Amphipod-sea anemone associations have evolved independently many times and do not seem to be of great evolutionary antiquity.

\section{INTRODUCTION}

The crustaceans of the order Amphipoda are according to most biology textbooks free-living animals, with some old and invariably cited exceptions such as the whale-lice on whales, Hyperia species on medusae and some Dexaminidae in sponges and tunicates. This view is certainly incorrect for the suborder Hyperiidea, most of which are obligate symbionts of gelatinous zooplankton (cf. Laval, 1980). Also among the Gammaridea and Caprellidea a large number of species live in association with a wide spectrum of invertebrates (e.g. Arndt, 1933; Vader, 1970b, 1971a-c, 1972, 1979, in prep.), fish (no review paper published) or even sea turtles (Barnard, 1967). These associations have in the past been largely overlooked or looked upon as incidental, in part because amphipods generally become easily dislodged from their host on capture, in part because most amphipod workers were museum taxonomists. With the advent of SCUBA-diving as a biological tool, large numbers of amphipod associations are now being discovered, although only few have been studied thoroughly.

Sea anemones are well-known as hosts of many symbionts: fishes (cf. Allen, 1972), shrimps, porcelain crabs, hermit crabs and spider crabs (Ross, 1967, 1971, 1974; Wolff, 1972; Suzuki \& Hayashi, 1977), mysids (Clarke, 1955) and copepods (Bouligand, 1966; Gotto, 1979; Humes, 1982); such associations seem to be especially common in tropical waters. These associations occur in spite of the fact that most anemones are active predators and often feed on prey in the same size ranges as the associates, which they catch with the help of numerous batteries of toxic nematocysts and clinging spirocysts. Furthermore, digestion is largely extracellular and large amounts of proteolytic enzymes, also containing chitinases, are secreted into the gastrovascular cavity. The copious mucus production of sea anemones may also pose problems.

Once symbionts have been able to overcome these barriers, however, sea anemones offer many obvious advantages as hosts. They are long-lived animals and offer excellent protection, even to such large associates as hermit crabs (Ross, 1971; McLean \& Mariscal, 1973). Sea anemones may collect more food than they can eat quickly, while the semi-digested and ejected food remains are also of high nutritive 